\title{
ENSINO REMOTO NA EDUCAÇÃO SUPERIOR: IMPACTOS NA FORMAÇÃO INICIAL DOCENTE
}

\author{
ENSEÑANZA REMOTA EN LA ENSEÑANZA SUPERIOR: IMPACTOS EN LA \\ FORMACIÓN INICIAL DEL PROFESORADO
}

\section{REMOTE TEACHING IN HIGHER EDUCATION: IMPACTS ON INITIAL TEACHER EDUCATION}

\author{
Joselma SILVA ${ }^{1}$ \\ Ilsa do Carmo Vieira GOULART ${ }^{2}$ \\ Giovanna Rodrigues CABRAL ${ }^{3}$
}

RESUMO: Ao apontar situações sociais que impactam no campo educacional, emergem inquietações acerca de ações decorrentes de medidas de prevenção da pandemia causada pela Covid-19. Nessa direção, este artigo objetiva refletir sobre as percepções de estudantes do curso de Pedagogia, da Universidade Federal de Lavras, Minas Gerais, a partir da experiência do ensino remoto, verificando impactos no processo de formação inicial dos estudantes. A reflexão teórica parte de diferentes legislações sobre o ensino remoto; distinção entre ensino remoto e educação a distância; o uso das tecnologias e a pandemia do Covid-19. O estudo destaca percepções em relação aos modos de organização pessoal do tempo, do processo de autonomia de estudos, de habilidades de uso de recursos digitais ou da inviabilidade de acesso à rede de internet, o que gerou impactos no processo de aprendizagem dos estudantes e nos modos de relação com os diferentes contextos formativos.

PALAVRAS-CHAVE: Formação inicial. Ensino remoto. Educação superior.

RESUMEN: Al señalar las situaciones sociales que afectan al campo educativo, surgen preocupaciones sobre las acciones resultantes de las medidas de prevención de la pandemia causadas por Covid-19. En este sentido, este artículo tiene como objetivo reflexionar sobre las percepciones de los estudiantes de la carrera de Pedagogía, de la Universidad Federal de Lavras, Minas Gerais, a partir de la experiencia de la enseñanza a distancia, verificando los impactos en el proceso de formación inicial de los estudiantes. La reflexión teórica es parte de diferentes leyes sobre educación remota; distinción entre el aprendizaje a distancia y la educación a distancia; el uso de tecnologías y la pandemia covid-19. El estudio destaca las percepciones sobre los modos de organización personal del tiempo, el proceso de autonomía

\footnotetext{
${ }^{1}$ Secretaria Municipal de Educação de Lavras (SME), Lavras - MG - Brasil. Professora da Rede Municipal. Mestrado em Educação (UFLA). ORCID: https://orcid.org/0000-0002-5673-8923. E-mail: joselma.jc@hotmail.com

${ }^{2}$ Universidade Federal de Lavras (UFLA), Lavras - MG - Brasil. Professora no Departamento de Educação e no Programa de Pós-Graduação em Educação. Doutorado em Educação (UNICAMP). ORCID: https://orcid.org/0000-0002-9469-2962. E-mail: ilsa.goulart@ufla.br

${ }^{3}$ Universidade Federal de Lavras (UFLA), Lavras - MG - Brasil. Professora no Departamento de Educação e no Programa de Pós-Graduação em Educação. Doutorado em Educação (PUC-Rio). ORCID: https://orcid.org/00000002-4780-516X. E-mail: giovanna.cabral@ufla.br
} 
de los estudios, las habilidades de uso de los recursos digitales o la infeabilidad de acceso a la red de Internet, que generó impactos en el proceso de aprendizaje de los estudiantes y en los modos de relación con los diferentes contextos formativos.

PALABRAS CLAVE: Formación inicial. Educación remota. Enseñanza superior.

ABSTRACT: By pointing out social situations that impact the educational field, concerns arise about actions resulting from pandemic prevention measures caused by Covid-19. In this Direction, this article aims to reflect on the perceptions of students of the Pedagogy course, from the Federal University of Lavras, Minas Gerais, from the experience of remote teaching, verifying impacts on the initial education process of students. The reflection is part of different laws on remote education; distinction between remote teaching and distance education; the use of technologies and the covid-19 pandemic. The study highlights perceptions regarding the modes of personal organization of time, the process of autonomy of studies, skills of use of digital resources or the unfeasibility of access to the Internet network, which generated impacts on the learning process of students and on the modes of relationship with the different formative contexts.

KEYWORDS: Initial education. Remote teaching. Higher education.

\section{Introdução}

As transformações fazem parte da vida do ser humano, sejam de ordem social, econômica, política, religiosa, cultural, tecnológica, educacional, entre outras, o que desencadeiam ações e modos distintos de comunicação e de interação, num processo de ajustamento das práticas cotidianas pessoais e profissionais. Isso não seria diferente quando se trata da educação formal presente nas agências formadoras em suas etapas e modalidades.

Nesse sentido, em um piscar de olhos, percebemos que a cada ano vivido, nos tornamos pessoas cada vez mais inseridas neste universo de instabilidades e mudanças e, certamente, vivemos momentos atuais, em que as 24 horas de um dia parecem pouco tempo para o cumprimento de toda a nossa agenda diária, buscamos a agilidade, a flexibilidade e a expansividade do tempo, na conquista do espaço (BAUMAN, 2001). Diante disto, a gestão do tempo é um desafio que impera na sociedade atual, visto que uma unidade de tempo não equivale a uma unidade de sentido, de acontecimentos ordenados e previstos, pois se trata da imprevisibilidade, do por vir (SKLIAR, 2014).

Partindo deste pensamento, a corrida desenfreada contra o tempo em busca da realização de desejos e necessidades tornou-se primordial no cotidiano do ser humano, sem exercer juízo de valor entre certo e errado. Trata-se de uma realidade do presente no contexto atual. Tudo deve ser rápido, de fácil acesso, às vezes, sem muita interação social, sem diálogo. Muitas ações 
devem ser práticas e pontuais, porque o mercado de trabalho e a sociedade solicitam das pessoas este tipo de ajustamento. Portanto, a agilidade e a competência no que se faz é o que se espera para bons profissionais. E corroborando com essa fluidez e reorganização dos tempos e espaços temos as tecnologias que ampliam e modificam as formas de ser e estar no mundo, encurtando distância e modificando as formas de interação entre as pessoas (BAUMAN, 2014).

$\mathrm{O}$ ano de 2020 surpreendeu a sociedade pelo enfrentamento de uma pandemia que trouxe inúmeras consequências à vida da população mundial. Para diminuir o avanço do vírus e minimizar o seu impacto nos sistemas de saúde, instaurou-se no mundo medidas de higiene pessoal e coletiva e o isolamento social, que acarretou novas adaptações para o mundo do trabalho e para a vida acadêmica, estabelecendo novas formas e rotinas para cumprimento de atividades diárias.

Com a velocidade do contágio e os riscos de morte maiores para pessoas idosas e com doenças pré-existentes, a COVID 19 se tornou uma doença a ser combatida por todos e seus impactos já são sentidos nas áreas sociais e econômicas com a supressão, redução e/ou suspensão de postos de trabalho e diminuição do poder de compra da população; nas áreas pessoais, com instabilidade emocional e adoecimento pelo confinamento das pessoas nas suas casas, sem contato social; na área educacional, com a interrupção das aulas da Educação Básica e Superior, deixando milhões de profissionais da educação e estudantes sem acesso às escolas e às instituições de educação superior, dentro outras áreas impactadas.

$\mathrm{Na}$ esfera educacional, que é a que nos interessa neste artigo, observamos a corrida das instituições de Educação Superior, de seus profissionais e estudantes para ajustarem suas ações à nova realidade que se configurou, a fim de não comprometer o tempo de estudo. Diante da permanência das recomendações de isolamento e distanciamento a instauração do ensino remoto emergencial foi a estratégia utilizada pelas instituições para minimizar as lacunas deixadas no ensino no Brasil. Assim, as redes de Educação Superior de todo o país estão enfrentando o imenso desafio de garantir a aprendizagem dos seus estudantes em tempos de isolamento social e fechamento das escolas por conta do Coronavírus (COVID-19) desde o início do ano de 2020.

É em meio a esse cenário que neste artigo nos propomos a apresentar uma experiência formativa de ensino remoto emergencial (ERE) no curso de Pedagogia, vivenciado na Universidade Federal de Lavras, Minas Gerias. O ERE para os semestres letivos de 2020/1 e 2020/2 foi estabelecido nesta instituição de ensino pelas Resoluções 059/2020 (UFLA, 2020) e 089/2020 (UFLA, 2020), a partir do Parecer CNE/CP n 5, de 28 de abril de 2020 (BRASIL, 2020), do Conselho Nacional de Educação, que regulamentou a reorganização do Calendário 
Escolar e da possibilidade de cômputo de atividades não presenciais para fins de cumprimento da carga horária mínima anual, em razão da Pandemia da COVID-19.

Assim, este artigo tem como objetivo refletir sobre a percepção de estudantes de Pedagogia, da Universidade Federal de Lavras, a partir da experiência do ensino remoto emergencial. O levantamento dos dados foi realizado por meio da aplicação de questionário a estudantes do curso de Pedagogia matriculados e frequentes no período de 2020/1 (maio a setembro), buscando identificar as suas percepções sobre a organização proposta por disciplinas em ensino remoto emergencial e possíveis impactos no processo de formação inicial dos estudantes.

Dentre os aportes teóricos, destacamos as legislações do Ministério da Educação sobre o Parecer CNE/CP n ${ }^{\circ}$ 5, de 28 de abril de 2020 (BRASIL, 2020), que regulamenta sobre o ensino remoto em decorrência da pandemia da COVID-19, Resolução 059/2020 (UFLA, 2020) e Resolução 089/2020 (UFLA, 2020) que tratam especificamente das orientações sobre o ensino remoto na Universidade Federal de Lavras, em diálogo com outros autores que discutem sobre a temática.

\section{Ensino remoto e educação a distância: distanciamentos necessários}

Tendo como base a implantação do período de isolamento social no Brasil devido à pandemia de COVID-19, buscamos apresentar a estratégia planejada por órgãos governamentais para dar continuidade aos estudos dos processos de ensino e aprendizagem nos diversos níveis de escolaridade: o ensino remoto emergencial.

O Conselho Nacional de Educação (CNE) aprovou em 28 de abril de 2020 (BRASIL, 2020), a partir do parecer CNE/CP n ${ }^{0} 5 / 2020$ (BRASIL, 2020), normas que orientaram as instituições educacionais sobre a reestruturação do Calendário Escolar e a organização de atividades não presenciais, objetivando a retomada e conclusão do ano letivo (2020), flexibilizando o cômputo dos dias letivos anuais, mas garantindo a carga horária mínima de horas de estudo. O documento deixou evidente em sua análise, que reorganizar o calendário escolar seria um desafio, no sentido de levar em conta a realidade de cada rede de ensino no Brasil. Assim, o parecer CNE/CP no 5/2020 (BRASIL, 2020, p. 3) afirma que "É necessário considerar propostas que não aumentem a desigualdade ao mesmo tempo em que utilizem a oportunidade trazida por novas tecnologias digitais de informação e comunicação para criar formas de diminuição das desigualdades de aprendizado". 
Frente à regulamentação, o cuidado com a aprendizagem dos estudantes foi pensado de forma a garantir que todos tivessem direito aos processos de aprender e de que as metodologias utilizadas não causassem diferenças de oportunidades de acesso ao ensino. Partindo deste pressuposto, o parecer enumera um conjunto de estratégias que podem ser usadas, de acordo com a realidade local, para a retomada do ensino não presencial:

Assim sendo, as atividades pedagógicas não presenciais podem acontecer por meios digitais (vídeoaulas, conteúdos organizados em plataformas virtuais de ensino e aprendizagem, redes sociais, correio eletrônico, blogs, entre outros); por meio de programas de televisão ou rádio; pela adoção de material didático impresso com orientações pedagógicas distribuído aos alunos e seus pais ou responsáveis; e pela orientação de leitura, projetos, pesquisas, atividades e exercícios indicados nos materiais didáticos (BRASIL, 2020, p. 8-9).

Dessa forma, com a necessidade de adaptação a uma situação social, o Ministério da Educação, flexibilizou tempos e espaços escolares, fazendo emergir para a modalidade presencial uma nova forma de ensino e de aprendizagem que, de certa forma, já era utilizada por muitas instituições de Educação Superior se pensarmos nos cursos ofertados na modalidade à distância. Assim, à primeira vista e de forma aligeirada todas as respostas para os problemas atuais da educação recaíram no uso da modalidade a distância para o ensino presencial. No entanto, é importante destacar que o ERE e a Educação a Distância não podem ser compreendidos como sinônimos, nesse sentido Behar (2020), considera importante estabelecer a distinção entre essas expressões. Sobre o ERE, a autora pontua:

O termo "remoto" significa distante no espaço e se refere a um distanciamento geográfico. O ensino é considerado remoto porque os professores e alunos estão impedidos por decreto de frequentarem instituições educacionais para evitar a disseminação do vírus. É emergencial porquê do dia para noite o planejamento pedagógico para o ano letivo de 2020 teve que ser engavetado (BEHAR, 2020).

Assim, com base no contexto mundial de Pandemia e isolamento, foi preciso pensar em estratégias pedagógicas para minimizar os impactos da ausência do ensino presencial na formação dos estudantes. E muitas dessas estratégias recaíram no uso de recursos tecnológicos e meios digitais, como os ambientes virtuais de aprendizagem (AVA) e a internet. Trata-se de um ajuste temporário e emergencial, por isso, é tão difícil de ser implementado, pois, muitas vezes, as instituições de ensino não possuem infraestrutura e recursos tecnológicos para a organização do ERE, os professores não são qualificados e formados para a docência em meios digitais, tampouco possuem conhecimentos para fazerem a adaptação de seus materiais para disponibilização nos AVA e os estudantes, além de não terem em casa os equipamentos 
necessários para a frequências nas aulas remotas e acesso aos materiais, não apresentam a disciplina necessária para organizarem os tempos e espaço de estudos. Assim, Behar (2020) apresenta o ERE como uma nova modalidade de ensino que "pressupõe o distanciamento geográfico de professores e alunos e foi adotada de forma temporária nos diferentes níveis de ensino por instituições educacionais do mundo inteiro para que as atividades escolares não sejam interrompidas".

Nesse mesmo sentido, Hodges et al. (2020) apontam o ERE como uma mudança temporária da entrega de conteúdos curriculares para uma forma de oferta alternativa, devido à situação da crise. Envolve o uso de soluções de ensino totalmente remotas para as aulas previamente elaboradas no formato presencial. Monteiro $(2020$, p. 8$)$ acrescenta não se trata de uma simples transposição didática do presencial para o ensino a distância, pois a "[...] transposição didática implica que o professor seja capaz de fazer as transformações necessárias ao processo de ensino e aprendizagem, quer seja dos recursos a serem utilizados, quer seja do próprio saber", o que, nesse cenário, pode não ocorrer, pois todo o planejamento foi pensado para ocorrer de forma presencial e não remotamente.

Em relação à Educação a Distância $(\mathrm{EaD})$, enquanto modalidade de ensino que perpassa as etapas da educação, temos o Decreto n ${ }^{\circ}$ 9057/2017 (BRASIL, 2017) que a conceitua

Para os fins deste Decreto, considera-se educação a distância a modalidade educacional na qual a mediação didático-pedagógica nos processos de ensino e aprendizagem ocorra com a utilização de meios e tecnologias de informação e comunicação, com pessoal qualificado, com políticas de acesso, com acompanhamento e avaliação compatíveis, entre outros, e desenvolva atividades educativas por estudantes e profissionais da educação que estejam em lugares e tempos diversos.

Dessa definição depreendemos que a educação a distância apresenta um modo de funcionamento próprio, alicerçado em uma concepção didático-pedagógica que fundamenta os processos de ensino e de aprendizagem, com materiais, atividades e todo um design adequado às características dos cursos e contemplando o processo avaliativo discente. Ou seja, segundo Behar (2020) na EAD há um modelo pedagógico específico, voltado para alunos, professores, tutores, "[...] constituído por uma arquitetura pedagógica composta pelos aspectos organizacionais, de conteúdo, metodológicos, tecnológicos e as estratégias pedagógicas a serem empregadas".

Com base no que Mill, Ribeiro e Oliveira (2010) discutem, o ensino moldado à distância conduz o docente a tomar uma posição de um olhar coletivo. O professor precisa contar com o apoio de vários profissionais, tais como: outros professores, técnicos, tutores, supervisores, 
coordenadores, enfim, toda a equipe envolvida para que a disciplina aconteça. Neste sentido, segundo o autor, este processo torna-se possível devido à "polidocência" que constitui uma característica da equipe que trabalha conjuntamente para dinamizar os saberes do professor (MILL; RIBEIRO; OLIVEIRA, 2010).

Ainda, há que se destacar da definição a expressão "com pessoal qualificado", em que entendemos que tanto o ensino presencial quanto a educação a distância ensejam a presença de profissionais qualificados para a execução de suas atividades. No entanto, o legislador apenas quis destacar as competências específicas voltadas para os usos dos AVA e os meios digitais como requisitos para a docência e a mediação na educação a distância e não fazer a dicotomia entre as modalidades, embora saibamos que essa separação aconteça, inclusive sob o viés da qualidade da formação ofertada.

Corroborando sobre as distinções entre ERE e EaD, Hodges et al. (2020) evidenciam que, no contexto da pandemia da Covid-19, as instituições de ensino têm implementado respostas rápidas para retorno das atividades, que envolvem equivocadamente considerar o uso dos meios digitais e dos AVA como se fossem experiências de EaD. E destaca que esses movimentos online das instituições no período da pandemia não é a implementação da $\mathrm{EaD}$, mas sim, a obtenção do máximo de proveito de recursos e possibilidades no formato online.

Arruda (2020), em concordância com os autores Hodges et al. (2020), afirma que a educação remota online digital se diferencia da $\mathrm{EaD}$ pelo caráter emergencial que propõe usos e apropriações das tecnologias em circunstâncias específicas de atendimento, sendo que ou em que outrora existia regularmente a educação presencial.

Atender, por meio de tecnologias digitais, alunos afetados pelo fechamento das escolas, não é a mesma coisa que implantar Educação a Distância, ainda que tecnicamente e conceitualmente refira-se à mediação do ensino e da aprendizagem por meio de tecnologias. A EaD envolve planejamento anterior, consideração sobre perfil de aluno e docente, desenvolvimento a médio e longo prazo de estratégias de ensino e aprendizagem que levem em consideração as dimensões síncronas e assíncronas da EaD, envolve a participação de diferentes profissionais para o desenvolvimento de produtos que tenham, além da qualidade pedagógica, qualidade estética que é elaborada por profissionais que apoiam o professor na edição de materiais diversos (ARRUDA, 2020, p. 9).

Por fim, diante do contexto atual, é preciso pensar o ERE como um princípio importante para manter o vínculo entre estudantes, professores e demais profissionais da Educação o que, do contrário, manteríamos o afastamento, por um longo período de tempo, de estudantes dos espaços escolares (físicos e virtuais), comprometendo ainda mais sua formação. Ainda, é preciso destacar que o ERE não se restringe à existência ou não de acesso tecnológico e dos 
meios digitais para que aconteça. Tudo irá depender da reorganização das instituições de ensino, no caso da Ensino Superior, que devem levar em conta o contexto local, o perfil do público atendido para efetivarem um planejamento que de fato seja possível de ser colocado em prática.

\section{O ensino remoto na Universidade Federal de Lavras}

No âmbito da Universidade Federal de Lavras, o plano de retomada das atividades de forma remota não tardou a ser pensado; a instituição ficou pouco mais de um mês com suas atividades suspensas, tempo esse usado para reorganizar o calendário letivo, ajustar os sistemas e publicar normativas sobre o ERE na instituição. Além disso, este período foi destinado ainda para realizar formações junto aos docentes, para orientar sobre os usos dos meios digitais e para a adaptação dos materiais didáticos, bem como junto aos estudantes, buscar apresentar estratégias de organização dos tempos e espaços e de estudos individuais.

Em maio de 2020 retomou-se o semestre letivo de 2020/1, iniciado em fevereiro e suspenso em março do mesmo ano. Várias normativas foram publicadas e divulgadas pela PróReitoria de Graduação para orientar os processos acadêmicos na instituição, dentre elas, a Resolução 059/2020 (UFLA, 2020) que autorizou a retomada das atividades letivas referentes ao primeiro semestre letivo de 2020 suspensas, instituindo o modelo de ensino remoto emergencial como estratégia para essa retomada. A Resolução definiu em seu artigo $2^{\circ}$, inciso $1^{\mathrm{o}}$, o ERE como "[...] o conjunto de atividades de ensino-aprendizagem desenvolvidas com a mediação de tecnologias digitais de informação e comunicação que abrangem estudos de forma orientada e autônoma, bem como aulas expositivas gravadas e aulas dialogadas transmitidas por Webconferência" (UFLA, 2020).

Ainda, para a condução das rotinas didáticas, além da atualização dos planos de ensino a partir do novo formato instituído, a Resolução previu os Roteiros de Estudos Orientados (REO), que deveriam ser elaborados pelos docentes, segundo modelo, e disponibilizado no AVA da disciplina para consulta dos estudantes. Conforme artigo $5^{\circ}$, inciso $2^{\circ}$ da Resolução 059/2020 (UFLA, 2020):

Cada REO, elaborado pelo professor responsável pelo componente curricular, será o documento mínimo para confirmação da atividade de ERE e deve conter a delimitação de um tema de estudo, apresentar objetivos de aprendizagem claros relacionados ao tema delimitado, definir um conjunto de orientações para o alcance desses objetivos, apresentar as referências de estudo indicando materiais e/ou mídias onde o estudante pode ter acesso a elas e solicitar o desenvolvimento de um produto final. 
A aplicação dos REO pôde variar de semanal a quinzenal e sua elaboração pressupôs a indicação de materiais didáticos que contenham os conteúdos estudados, bem como, quando necessário, a previsão de aulas gravadas ou outras formas de apresentação do conteúdo e de interação com os estudantes. A recomendação inicial era que fossem evitados os encontros com estudantes e a ministração de aulas de forma síncrona e, caso esses recursos fossem usados, que a gravação fosse disponibilizada para aqueles estudantes que não puderam assistir no dia e horário agendados. Ainda, o artigo $11^{\circ}$ da Resolução 059/2020 (UFLA, 2020) definiu que o "conjunto das atividades desenvolvidas na forma de REO deve gerar, pelo menos, um produto de autoria do estudante (vídeo, texto, resenha, artefato, objeto, tecnologia, método, resolução de problema, projeto elaborado, entre outros)", estabelecendo assim, os critérios avaliativos previstos para o período.

Esse conjunto de normativas e os aspectos diretivos e pouco flexíveis dos encaminhamentos adotados na instituição foram objetos de reclamação e resistências por parte de membros da comunidade, de forma geral. Mas entendemos que, frente aos desafios impostos e do curto prazo de tempo para a construção de um novo modelo, a instituição lançou mão de documentos norteadores que garantissem um padrão mínimo de qualidade para os processos de ensino e de aprendizagem, ao mesmo tempo em que buscava contemplar todas as possibilidades burocráticas que o ERE podia gerar.

O processo de instituição do ERE foi avaliado processualmente ao longo do semestre e, no final de julho de 2020, uma nova resolução, a Resolução 089/2020 (UFLA, 2020), foi publicada para término do primeiro semestre letivo de 2020 e implementada para o segundo semestre letivo de 2020 na instituição, contemplando assim, muitos aspectos levantados pela comunidade e flexibilizando o REO, garantindo a autonomia docente na organização dos processos didáticos.

Os docentes do curso de Pedagogia da UFLA observaram as normativas da instituição e organizaram as disciplinas do segundo semestre, conforme as orientações da Resolução 089/2020 (UFLA, 2020). O conteúdo curricular das disciplinas foi ministrado por meio dos Roteiros de Estudos Orientados (REO), gerenciadas na plataforma da universidade, denominada "Campus Virtual", com salas virtuais em que os docentes responsáveis faziam as postagens dos materiais e das atividades. Os roteiros eram descritos e postados na plataforma quinzenalmente, divididos em unidades temáticas, propondo: (a) leituras teóricas disponíveis em online, como artigos científicos, e-books, capítulos de livros digitalizados; (b) vídeos ou documentários sobre a temática; (c) atividades a serem realizadas pelos estudantes sobre a 
temática proposta e (d) aulas agendadas de forma síncrona na plataforma Google Meet, gravadas e disponibilizadas para acompanhamento de forma assíncrona.

\section{Metodologia}

A Universidade Federal de Lavras (UFLA), com base na Resolução 089/2020 (UFLA, 2020,), em seu Art. $2^{\circ}$, discorre sobre os cursos presenciais, os quais foram conduzidos por meio de "Estudo Remoto emergencial (ERE)", refazendo o calendário acadêmico, com encerramento das atividades do primeiro semestre para 15 de setembro de 2020. Assim, a resolução define em seu Art $2^{\circ}$, parágrafo $1^{\circ}$, o ERE como:

[...] o conjunto de atividades de ensino-aprendizagem desenvolvidas com a mediação de tecnologias digitais de informação e comunicação que abrangem estudos de forma orientada e autônoma, bem como aulas expositivas gravadas e aulas dialogadas transmitidas por Webconferência (UFLA, 2020, p. 10).

A partir deste início, propomos a refletir sobre os impactos que o ensino remoto emergencial provocou nos processos de ensino e aprendizagem de estudantes do curso de Pedagogia da Universidade Federal de Lavras, bem como as diversas dimensões que têm influenciado os alunos neste processo. Buscamos fundamentar em André (2012, p. 17) a abordagem qualitativa com objetivo descritiva para a coleta dos dados, sendo esta "uma visão holística dos fenômenos, isto é, que leve em conta todos os componentes de uma situação em suas interações e influências recíprocas".

Consideramos que as mudanças inesperadas quando percorremos caminhos planejados devem ser consideradas e diante dos desafios postos, vários aspectos sofrem alterações e adaptações para que as relações sociais continuem sendo suportes para uma efetiva aprendizagem, mesmo que de forma virtual, visando o mesmo objetivo traçado no início do percurso.

Após um mês de vivências das atividades propostas pelos REOS (Roteiro de Estudos Orientados), foi realizado um questionário para a verificação do andamento e dos desafios encontrados pelos estudantes do quinto período do curso de Pedagogia da Universidade Federal de Lavras/MG. O questionário compôs-se de 6 questões fechadas, disponibilizado pela ferramenta Google Forms. 


\section{Análise e discussão dos resultados}

Nesta seção serão apresentados e discutidos os dados coletados dos X estudantes participantes desta pesquisa.

A primeira questão remeteu à quantidade de atividades propostas pelos docentes nos Roteiros de Estudos Orientados.

Figura 1 - Questionário Pedagogia (questão 1)
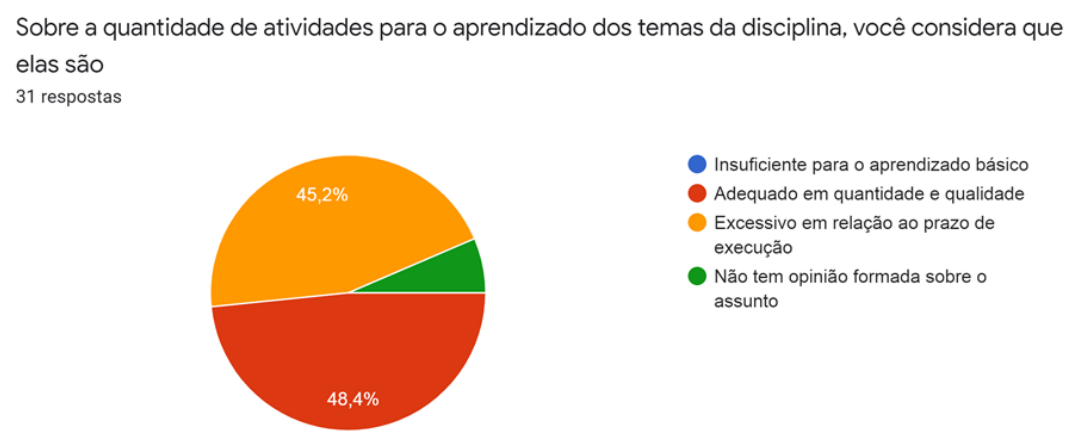

Insuficiente para o aprendizado básico

Adequado em quantidade e qualidade

Excessivo em relação ao prazo de

execução

Não tem opinião formada sobre o

assunto

Fonte: Dados da pesquisa

Destacamos que os estudantes manifestaram inquietação em relação aos prazos estipulados para realização das atividades propostas pelos REO, uma vez que num período de quinze dias, os estudantes deveriam desenvolver propostas de leitura teóricas, atividades e participação em aulas síncronas de seis disciplinas diferentes no curso de Pedagogia, o que acarretou, inicialmente, o acúmulo de ações de estudos, em que se evidencia na questão 4.

Figura 2 - Questionário Pedagogia (questão 4)

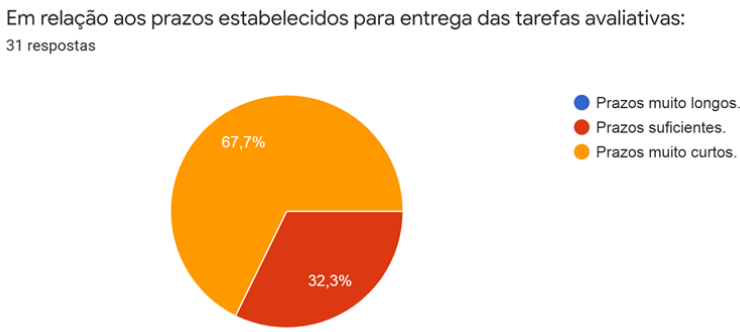

Fonte: Dados da pesquisa

A porcentagem de $67,7 \%$ demonstra uma percepção dos estudantes de que o tempo de elaboração das atividades propostas é insuficiente, tendo em vista o fator da condição social de 
isolamento, exigindo a organização do tempo para se dedicarem às atividades acadêmicas de estudos, ao trabalho, às atividades e afazeres pessoais, o que implicou no gerenciamento espaçotempo evidenciado na questão 3 .

Figura 3 - Questionário Pedagogia (questão 5)

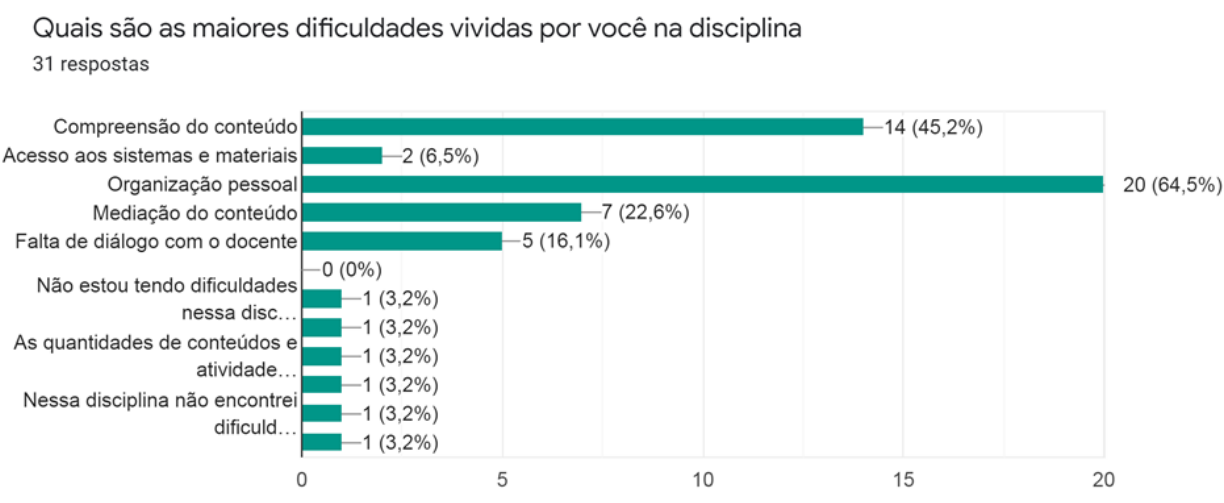

Fonte: Dados da pesquisa

Analisando os resultados do gráfico, poderíamos destacar muitos pontos de discussão, porém nos atentamos às implicações de maior impacto, como: a "organização pessoal" e a "compreensão do conteúdo". A referência à organização pessoal como maior fator de dificuldade para o desenvolvimento da disciplina nos indica a percepção dos estudantes em relação às limitações de gerenciamento do planejamento do tempo para a dedicação ao estudo. A temeridade do tempo pode ser compreendida mediante às ações, ao posicionamento e/ou às respostas que se exigem dos sujeitos, como descreve Skliar $(2014$, p. 44), “[...] uma unidade do tempo é exigir tanto quanto um segundo. Exigir: pedir, assumir, tomar, roubar, sentir".

Quanto à "compreensão do conteúdo", remonta a uma percepção em relação a autonomia de estudo, o que requer dos estudantes um conhecimento do processo de autoaprendizagem, haja vista que o REO ofereceu estratégias de condução de um determinado conteúdo. Entretanto, o percurso de estudo a ser realizado foi de responsabilidade do estudante. O que demonstra os desafios do que Freire (1996) denomina de passagem da heteronomia para a autonomia. Deste modo, vencer as ações de dependência no processo educativo emergiu nas situações de estudo provocadas pelo REO, em que “[...] o essencial das relações entre educador e educando, entre autoridade e liberdades, entre pais, mães, filhos e fillhas é a reinvenção do ser humano no aprendizado da autonomia" (FREIRE, 1996). 
Nessa direção, ressaltamos que o diálogo incidiu como ação formativa de amenização dos impactos frente às exigências de capacidades de um ensino remoto, o que requereu a flexibilização de ações, permitindo aos estudantes e professores elegerem distintas estratégias de formação, reconhecendo espaços e momentos de aprendizagem mais eficientes.

Outro impacto referiu-se ao uso das ferramentas tecnológicas, tais como ou a saber: (a) com o surgimento da pandemia, muitos estudantes que não moram na cidade Lavras/MG retornaram para suas casas e, muitos, não possuíam acesso a uma rede de internet; (b) estudantes que não dispunham de computadores, somente celular, impediu que as atividades fossem realizadas no prazo estipulado e com eficiência, pois dependiam da conexão da operadora do aparelho; (c) outros possuíam aparelhos, tanto computadores quanto celulares, porém se deslocaram para a localidades rurais; (d) houve ainda aqueles estudantes que passaram por transtornos psicológicos e demoraram a se adaptar a ensino remoto.

Percebemos que o ensino remoto exigiu a habilidade de buscar a interação entre educação e recursos tecnológicos, de forma que pudessem contribuir para o processo de ensino e aprendizagem nas diferentes formas de comunicação. Logo, no atual contexto educacional, além da certificação, da qualificação e da atualização profissional, dos diversos saberes que emana do tempo de experiência, a docência se refere a uma profissão que também necessita de conhecimentos tecnológicos a fim de estar conectada à realidade dos estudantes. Nesse sentido, o ERE reforçou a necessidade de se desenvolver outras formas de ensinar. Assim, segundo Bacich e Moran (2018), o aluno torna-se o sujeito ativo na participação deste processo de aprendizagem experimentando um espaço de invenção, mediado pelo professor.

Toebe (2016) nos faz entender que os instrumentos tecnológicos são capazes de contribuir no aprimoramento das práticas pedagógicas e promover novas metodologias no currículo da Educação Superior no que se refere à formação inicial de professores. Saccol, Schlemmer e Barbosa (2010) reforçam que as Tecnologias da Informação e Comunicação são elementos que dão suporte para que o educador se desenvolva profissionalmente. Contudo, aponta uma ressalva dizendo que a educação "[...] envolve todos os processos de aprendizagem apoiados pelas diversas tecnologias da informação e comunicação disponíveis, incluindo as tecnologias móveis e sem fio, mas não se limitando a elas" (SACCOL; SCHLEMMER; BARBOSA, 2010, p. 29). 


\section{Considerações finais}

As incertezas da atualidade nos levaram a caminhar diariamente de modo reflexivo. A pandemia da Covid-19 que se instaurou no mundo contemporâneo demandou uma superação de desafios em todas as esferas sociais. Exigiu do contexto educacional, ações emergenciais necessárias para garantir a continuidade da Educação Superior.

Em situações inesperadas como uma pandemia, fez-se necessária a implementação de políticas públicas que tenham planos de ação com o objetivo de que o direito ao ensino alcance a todos. O formato de ensino remoto emergencial foi inusitado e exigiu a reconfiguração dos e nos processos de ensino e aprendizagem, desencadeando propostas de ações, modos de relações, para professores, estudantes e para os demais profissionais do suporte técnico. Logo, foi preciso um agir rápido, preciso e consciente por parte da administração da UFLA de forma a movimentar todo o currículo, calendário, ação dos docentes, a rotina dos estudantes. Enfim, uma nova configuração precisou ser reinventada para que os estudos não se perdessem de vista. Com isso, os recursos tecnológicos se mostraram aliados ao sistema educacional sob a orientação docente, o que provocou impactos nos processos de ensino e aprendizagem.

As respostas demonstradas por meio do questionário nos permitem destacar as percepções em relação aos modos de organização do tempo, do processo de autonomia de estudos, de habilidades de uso de recursos digitais ou da inviabilidade de acesso à rede de internet, como impactos do ensino remoto na aprendizagem dos estudantes. Nesse sentido, consideramos que os processos de ensino e aprendizagem mediados por recursos digitais podem ser potencializados, o que exige ações de mediação, de diálogo e de flexibilização dos docentes, de modo a gerenciar saberes, criar situações de motivação e de criação de novas práticas educativas. Segundo Freire (1996, p. 69), “aprender é uma aventura criadora”, que frente aos impactos puderam gerar situações de reflexão dos processos de ensino e de aprendizagem, de modo a considerar que "[...] aprender para nós é construir, reconstruir, constatar para mudar, o que não se faz sem abertura ao risco e à aventura do espírito".

Conforme os estudos de Tardif (2002, p. 21), as experiências que surgem no decorrer do tempo na docência, são múltiplas, por isso, é necessário "mobilizar uma ampla variedade de saberes reutilizando-os no trabalho para adaptá-los e transformá-los pelo e para o trabalho". Nesse sentido, retomamos a questão do tempo, como elemento centralizador das ações, que na fluidez moderna, o tempo e o espaço demandam pelo multitasking, ou seja, a habilidade de realizar múltiplas atividades no mesmo tempo (BAUMAN, 2001). Frente à imprevisibilidade ocasionadas pelas incertezas de cada instante exigiu-se posicionamentos para se otimizar o 
tempo de estudo, considerados pouco adequados, mas o possível naquele momento, pois assim, como afirma Skliar (2014, p. 44), entendemos que "[...] uma unidade de tempo não é correta nem incorreta, nem justa nem injusta, nem sábia nem ignorante: sucede, acontece".

\section{REFERÊNCIAS}

ANDRÉ, M. E. D. A. Etnografia da prática escolar. 18 ed. Campinas: Papirus, 2012.

ARRUDA, E. P. Educação remota emergencial: elementos para políticas públicas na educação brasileira em tempos de Covid-19. Em Rede - Revista De Educação a Distância, Porto Alegre, v. 7, n. 1, p. 257-275, 2020.

BACICH, L.; MORAN. J. (Org.). Metodologias ativas para uma educação inovadora: uma abordagem teórico-prática. Porto Alegre: Penso, 2018.

BAUMAN, Z. Modernidade líquida. Trad. Plínio Dentzien. Rio de Janeiro: Jorge Zahar, 2001.

BEHAR, P. A. O ensino remoto emergencial e a educação a distância. Disponível em: https://www.ufrgs.br/coronavirus/base/artigo-o-ensino-remoto-emergencial-e-a-educacao-a-distancia/. Acesso em: 6 jul. 2020.

BRASIL. Conselho Nacional de Educação. Decreto n. 9057, de 25 de maio de 2017. Regulamenta o art. 80 da Lei n. 9.394, de 20 de dezembro de 1996, que estabelece as diretrizes e bases da educação nacional. Brasília, DF: CNE, 26 maio 2017. Disponível em:

http://www.planalto.gov.br/ccivil_03/_ato2015-2018/2017/decreto/d9057.htm. Acesso em: 7 jul. 2020.

BRASIL. Conselho Nacional de Educação. Portaria n. 2.167, de 19 de dezembro de 2019. Diretrizes Curriculares Nacionais para a Formação Inicial de Professores para a Educação Básica e Base Nacional Comum para a Formação Inicial de Professores da Educação Básica (BNC-Formação). Brasília, DF: CNE, 20 dez. 2019. Disponível em: https:/www.in.gov.br/en/web/dou/-/portaria-n2.167-de-19-de-dezembro-de-2019-234650456. Acesso em: 7 jul. 2020.

BRASIL. Conselho Nacional de Educação. Portaria n. 2117, de 6 de dezembro de 2019. Dispõe sobre a oferta de carga horária na modalidade de Ensino a Distância - EaD em cursos de graduação presenciais. Brasília, DF: CNE, 11 dez. 2019. Disponível em: http://www.in.gov.br/en/web/dou//portaria-n-2.117-de-6-de-dezembro-de-2019-232670913. Acesso em: 7 jul. 2020.

BRASIL. Ministério da Educação. Conselho Nacional de Educação. Conselho Pleno. Parecer CNE/CP n. 5, de 28 de abril de 2020. Brasília, DF: MEC/CNE, 2020. Disponível em: $\mathrm{http} / / /$ portal.mec.gov.br/index.php?option=com_docman\&view=download\&alias=145011-pcp00520\&category_slug=marco-2020-pdf\&Itemid=30192. Acesso em: 7 jul. 2020.

BRASIL. Ministério da Educação. Conselho Nacional de Educação. Resolução CNE/CP n. 1 de 15 de maio de 2006. Institui as Diretrizes Curriculares Nacionais para Cursos de Graduação em Pedagogia, licenciatura. Portal MEC. Brasília: MEC/CNP/CP, 2006. Disponível em: http://portal.mec.gov.br/cne/arquivos/pdf/rcp01_06.pdf. Acesso em: 20 set. 2020.

BRASIL. Ministério da Educação. Lei n. 12.056, de 13 de outubro de 2009. Acrescenta parágrafos ao art. 62 da Lei n. 9.394, de 20 de dezembro de 1996, que estabelece as diretrizes e bases da educação nacional. Diário Oficial da União: Seção 1, Brasília, DF, p. 1, 14 out. 2009. PL 7515/2006

FREIRE, P. Pedagogia da autonomia. São Paulo: Paz e Terra, 1996. 
HODGES, Charles et al. The difference between emergency remote teaching and online learning. EDUCAUSE Review, 2020. Disponível em: https://er.educause.edu/articles/2020/3/the-differencebetween-emergency-remote-teaching-and-online-learning. Acesso em: 27 mar. 2020.

MILL, D. R. S.; RIBEIRO, L. R. C; OLIVEIRA, M. R.G. (Org.). Polidocência na educação a distância: múltiplos enfoques. São Carlos, SP: EdUFSCar, 2010.

MONTEIRO, S. S. (Re)inventar educação escolar no brasil em tempos da covid-19. Revista Augustus, Rio de Janeiro, v.25, n. 51, p. 237-254, jul./out. 2020. DOI:

https://doi.org/10.15202/1981896.2020v25n51p237

PRENSKY, M. Digital natives. Digital immigrants. On the Horizon, MCB University Press, v. 9, n. 5, p. 1-6, oct. 2001. Disponível em: https://www.marcprensky.com/writing/Prensky\%20-

\%20Digital\%20Natives,\%20Digital\%20Immigrants\%20-\%20Part1.pdf. Acesso em: 02 jan. 2018.

SACCOL, A.; SCHLEMMER, E.; BARBOSA, J. M-learning eu-learning: novas perspectivas da aprendizagem móvel e ubíqua. São Paulo: Pearson, 2010.

SANTOS, E. Pesquisa-formação na cibercultura. Santo Tirso: White Books, 2019. Disponível em: http://www.edmeasantos.pro.br/assets/ livros/Livro\%20PESQUISA-

FORMA $\%$ C3\%87\%C3\%83O\%20NA\%20 CIBERCULTURA_E-BOOK.pdf. Acesso em: 20 set. 2020.

SKLIAR, C. Desobedecer a linguagem: educar. Trad. Giane Lessa. Belo Horizonte: Autentica, 2014.

TANIGUCHI, N. COVID-19: Ponto a ponto sobre o novo coronavírus. Fiocruz Brasília, 20 mar. 2020. Disponível em: https://www.fiocruzbrasilia.fiocruz.br/covid-19-ponto-a-ponto-do-novocoronavirus/. Acesso em: 7 ago. 2020.

TARDIF, M. Saberes docentes e formação profissional. Petrópolis: Vozes, 2002.

TOEBE, Í. C. D. Políticas públicas para integração de tecnologias educacionais na formação inicial de professores. Orientadora: Elena Maria Mallmann. 2016. 172 f. Dissertação (Mestrado em Educação) - Universidade Federal de Santa Maria, Santa Maria, 2016. Disponível em: https://bit.29 ly/3kJRGmN. Acesso em: 2 ago. 2020.

UNIVERSIDADE FEDERAL DE LAVRAS. Conselho de Ensino, Pesquisa e Extensão. Resolução n. 089, de 29 de julho de 2020. Altera a redação da Resolução n. 059/2020. Lavras, MG: CEPE, 2020. Disponível em: https://prograd.ufla.br/images/arquivos/legislações/5_089_29072020.pdf. Acesso em: 18 de setembro de 2020 .

UNIVERSIDADE FEDERAL DE LAVRAS. Conselho de Ensino, Pesquisa e Extensão. Resolução n. 059, de 14 de maio de 2020. Lavras, MG: CEPE, 2020. Disponível em: https://prograd.ufla.br/images/arquivos/legislações/5_089_29072020.pdf. Acesso em: 18 de setembro de 2020 . 


\section{Como referenciar este artigo}

SILVA, J.; GOULART, I. C. V.; CABRAL, G. R. Ensino remoto na educação superior: impactos na formação inicial docente. Revista Ibero-Americana de Estudos em Educação, Araraquara, v. 16, n. 2, p. 407-423, abr./jun. 2021. e-ISSN: 1982-5587. DOI: https://doi.org/10.21723/riaee.v16i2.14238

Submetido em: 29/09/2020

Revisões requeridas em: 26/12/2020

Aprovado em: 29/01/2021

Publicado em: 01/02/2021 